\title{
SENI CINTA; MENGGUGAT MASKULINITAS CINTA
}

\author{
Nikodemus Niko \\ Fakultas Ilmu Sosial dan Ilmu Politik Universitas Padjadjaran, Indonesia \\ nikodemusn@outlook.com
}

\begin{abstract}
This article using perspective of sociology of love in described love and see how love are very resilient with the Indonesia culture of patriarchy, included the description of masculinity love. Love used as an anomaly that is absolutely. Even absolute backfire for mankind cult of love. Sociology of love is not lay away to love as selfish person, on the other hand the power of love which dispatch people to peace. The illustrations and examples in this paper is based on knowledge and personal experience of mine. This paper write done by digging of various sources reference, which is I speculate by inference Freud said that love in now is still in animality essence. The masculine love is still adhered to this esence, and still alives in Nusantara's culture.
\end{abstract}

Kata Kunci: Love, Sociology of Love, Masculinity.

\begin{abstract}
Abstrak
Artikel ini menggunakan perspektif sosiologi cinta (sociology of love) dalam mendeskripsikan cinta dan melihat bagaimana cinta sangat kental dengan kultur Indonesia yang patriarki, termasuk di dalamnya deskripsi cinta yang maskulin. Cinta seringkali dijadikan sebuah anomali yang bersifat mutlak. Tak jarang kemutlakan itu sendiri yang menjadi bumerang bagi manusia pemuja cinta. Sosiologi cinta tidak meletakkan diri kepada cinta yang egois, sebaliknya kekuatan cinta yang menghantar manusia kepada perdamaian. Ilustrasi dan contoh pada paper ini berdasarkan pengetahuan dan pengalaman pribadi penulis. Penulisan paper ini dengan menggali berbagai sumber referensi, yang kemudian penulis berspekulasi dengan kesimpulan Freud yang mengatakan bahwa Cinta yang ada sekarang masih dalam esensi kebinatangan. Cinta yang maskulin diantaranya yang masih menganut esensi ini, dan hidup di tengahtengah budaya nusantara.
\end{abstract}

Keywords: Cinta, Sosiologi Cinta, Maskulinitas.

\section{PENDAHULUAN}

Cinta adalah seni yang paling tua dalam sejarah peradaban manusia. Tidak salah jika cinta disebutsebut sebagai fenomena masyarakat yang beradab. Cinta yang beradab keberadaannya tergolong baru, pada zaman dahulu sebagian besar sifat cinta adalah erotis, seperti pada cerita-cerita cinta dalam dongeng kuno. Bergler (dalam Krich, 2015) menyebutkan bahwa salah satu tanda cinta adalah dengan menyakiti diri sendiri. Roche (dalam Krich, 2015) menyatakan bahwa banyak orang menjadi putus asa karena cinta telah menjadi subjeka penelitian ilmiah, karena sebagian orang mengatakan bahwa cinta merupakan wilayah suci yang hanya bisa dimasuki oleh para penyair. Sementara yang lain berkata bahwa jika cinta ditempatkan dibawah pengamatan sains, maka ia akan dikuliti dari pesona dan keindahannya.

Setiap orang memiliki definisi sendiri-sendiri dalam mengartikan apa itu cinta. Tidak ada pembatasan sama sekali untuk cinta; bebas.
Namun, bukan berarti cinta adalah bebas nilai, sebaliknya cinta penuh dengan nilai-nilai kebaikan dan hidup. Karena cinta, seseorang bisa meluapkan kebahagiaannya dengan menangis, atau karena cinta seseorang menjadi tergila-gila kepada sesuatu; hal ini penuh dengan tanda-tanda nilai, yang jarang sekali dapat terdefinisi oleh orang lain. Saya setuju dengan pendapat Reik (dalam Krick, 2009) yang menyebutkan bahwa cinta tak sebatas ekspresi perasaan di antara dua jenis kelamin, lebih dari itu, menandakan perasaan kepada anggota keluarga, tetangga, teman bahkan musuh, kepada semua umat manusia, rumah, kelompok sosial atau rasial, bangsa, kepada segala sesuatu yang baik dan indah, juga kepada Tuhan. Cinta berarti tanpa batas, penuh dengan kebaikan.

Makna cinta yang beragam, kemudahan cinta beradaptasi dan polanya yang selalu dinamis tentu membuat saya terkagum akan cinta. Saya bisa saja mendefiniskan cinta sebagai cemburu yang berlebihan. Atau ada orang lain yang mengartikan cinta sebagai simbol kematian. Setiap kita bebas memiliki perspektif dalam mendefinisikan cinta. 
Beberapa ahli terkenal seperti Webster (dalam Krich, 2009) memberitahu kita bahwa sebenarnya cinta itu adalah perasaan. Dilain pihak Capellanus (dalam Krich, 2009) juga mengatakan bahwa cinta itu adalah penderitaan yang dibawa sejak kita lahir.

Secara konvensional apa yang dapat kita definisikan dari cinta? Cinta berasal dari kata Sansekerta 'Iubhayati' yang artinya adalah 'ia menginginkan'. Mungkin secara definisi masa lalu, terlalu banyak yang ditampilkan sebagai eufemisme yang tanpa deskripsi-abstrak, absurd-yang bermakna. Bahkan pada syair-syair yang diciptakan pada abad masa lalu, cinta seringkali ditampilkan sebagai sesuatu yang vulgar dan selalu dilambangkan dengan gairah seksual yang membara.

Banyak orang yang mengartikan sederhananya cinta; cukup dengan menatap wajah orang yang dicintai sedang tersenyum. Atau arti cinta sederhana yang muncul ketika seseorang mengungkapkan rasa bahagia; "aku bahagia saat menatapmu sedang minum air". Dan banyak lagi hal-hal atau cara-cara sederhana mengartikan cinta dalam kehidupan sehari-hari. Setiap orang tentu akan memiliki cara dan perspektif yang berbedabeda dalam mengartikan cinta. Pada narasi ekofeminisme, perempuan-perempuan di India mengekspresikan cinta mereka kepada alam dengan memeluk pohon-pohon (Shiva, 1997). Artinya bahwa cinta tidak hanya berbatas pada antar manusia saja, melainkan cinta dapat diekspresikan kepada setiap makhluk hidup seperti hewan dan tumbuhan.

Disebutkan oleh Fromm (dalam Krich, 2009) bahwa cinta merupakan fenomena masyarakat beradab. Cerita cinta yang realistis belum berusia lebih dari seratus tahun, yang sebelumnya sebagian besar sifat-sifat cinta adalah erotis. Banyak kita temukan pada teks-teks puisi di abad-abad masa lalu, dimana segala hal tentang cinta adalah cinta yang membangkitkan birahi seksual. Poin pentingnya adalah cinta yang erotis dan vulgar semestinya bukan hal baru tumbuh di kultur setiap masyarakat di seluruh muka bumi, termasuk di Indonesia.

Mungkin agak sedikit berbeda dari pemaknaan dari umumnya, Karl Mark memaknai cinta sebagai sesuatu hal yang penting karena menyangkut pada persoalan ekonomi. Pandangan Mark tentang cinta yang dikutip Povopa (2016) yaitu "Cinta dibentuk dan diproduksi oleh hubungan sosial yang konkret dan beredar di pasar pelaku persaingan yang tidak setara.... Beberapa orang diantaraya memberi wewenang kapasitas yang lebih besar untuk menentukan persyaratan dimana mereka menginginkan dicintai lebih daripada yang lain." Tergambar jelas bahwa pandangan Mark sangat maskulin-hal ini sejalan dengan narasi capitalism yang mendominasi-tentang cinta, bahwasannya cinta sarat dengan persyaratan-persyaratan (utamanya kapital).

Cinta yang sarat menampilkan sisi kapitalisme juga masih eksis sampai sekarang ini. Fenomena "ada uang, abang disayang" di dalam kultur Indonesia masih seringkali dijumpai pada kisah percintaan di desa-desa bahkan di perkotaan. Pepatah lama orang Melayu Pontianak yang menyebutkan bahwasannya "cinta tidak bisa merubah batu menjadi nasi" merupakan baluranbaluran kapitalisme yang menyusup ke dalam budaya patriarki. Perempuan-perempuan kemudian terkonstruksi untuk mencintai hanya laki-laki yang memiliki harta. Demikian pula dengan mahar-mahar dalam pernikahan, yang mana cinta sarat dengan narasi kapitalisme.

Cinta selalu ditampilkan pada dua insan atau lebih. Cinta yang melibatkan satu orang dalam emosionalitas cinta, jarang sekali dilihat sebagai cinta yang utuh. Padahal pada dasarnya mencintai diri sendiri adalah juga cinta yang utuh (bukan semata keegoisan diri); ketika kita mandi (membersihkan tubuh) merupakan bukti kecintaan kita terhadap tubuh kita sendiri. Namun, pada kasus ini cinta tidak dilihat sebagai cinta; melainkan 'mandi itu ya kewajiban' atau 'ya memang harus mandi' (kultur-yang berasal dari konstruksi). Kontruksikontruksi budaya yang ada dalam masyarakat pun, jarang sekali disebut sebagai cinta.

\section{METODE}

Objek dalam penelitian ini adalah cinta yang maskulin. Tulisan ini menggunakan metode penulisan deskriptif analitis, dengan mengekspolasi sumber-sumber teks tulisan tentang cinta. Data yang digunakan adalah data sekunder yang bersumber dari buku-buku, jurnal ilmiah, dan media online, serta data primer yang bersumber pada pengetahuan dan pengalaman pribadi penulis. Adapun yang menjadi fokus dalam tulisan ini adalah membongkar narasi-narasi cinta yang maskulin. Maskulinitas cinta tergambar pada tulisan-tulisan Freud (2009, 2017), Krich (2015) 
yang banyak menyunting tulisan-tulisan Sigmun Freud, Erich Fromm, Simone de Beauvoir, Pitirim Sorokin, dan beberapa ahli yang mengabadikan tulisan tentang cinta, Marcuse (2004), narasi cinta yang sarat dengan seks.

Cinta menurut Sorokin (dalam Krich, 2015) bagaikan fenomena gunung es, hanya bagian kecilnya saja yang kelihatan, itupun tidak sepenuhnya dapat dikenali. Dengan mengeksplorasi paradoksal cinta sebagai seni yang lemah lembut, santun dan agung, ternyata berbungkus dengan relasi kekerasan sebagai akibat dari cinta yang maskulin. Analisis konseptual yang ingin dicapai yaitu bagaimana pendekatan sosiologi memaknai cinta, bagaimana cinta itu sendiri merupakan seni yang erotis, dan bagaimana cinta yang maskulin tumbuh di dalam baluran budaya patriarkhi.

\section{HASIL DAN PEMBAHASAN}

Pada saat cinta menjadikan kita sebagai seorang partisan yang sudah matang untuk terlibat ke dalam hidup orang lain, secara tak terbatas cinta itu sendiri sudah memperkaya kehidupan kita dengan nilainilai kemanusiaan yang paling mulia. Sebab cinta lah yang mengisi kita dengan pengetahuan, partisipasi dan pengalaman bersama merupakan pengalaman terkaya bagi generasi. Pengalaman cinta sendiri lebih jauh lagi menumbuhkan perasaan tak kenal takut dan penuh kuasa.

Keberanian dan kemerdekaan dari cinta itu sendiri akan melahirkan kekuatan. Pada dasarnya cinta adalah konsep kebaikan itu sendiri, sehingga cinta akan membawa kehidupan kita pada hidup yang terhormat dan baik. Tetapi, jalan cinta tak hanya satu untuk menuju kebenaran dan kebaikan itu. Jalan berliku dan panjang untuk memahami arti cinta. Bagi saya semakin banyak kita melibatkan diri dan pikiran pada kebaikan adalah bukti cinta yang hidup dalam keseharian kita.

\section{Cinta dalam Imajinasi Sosiologi}

Sosiologi cinta sebenarnya sudah sangat lama menjadi kajian berbagai ilmuan di luar negeri. Namun dalam konteks ke-Indonesiaan masih belum terlalu umum di dengar masyarakat luas. Sosiologi dan cinta masih dipandang sebagai dua hal yang terpisah. Pada tulisan Pitirim Sorokin, yang diterbitkan di jurnal Humanistic Sociology, New York, mengemukakan bahwa kekuatan cinta yang kreatif sudah semestinya mengandung creative love, friendship, non-violence dan non-aggression (Krich, 2009).

Pandangan Sociology of Love sendiri mempercayai bahwa akan lebih banyak cinta yang muncul di dunia ini apabila cinta diletakkan pada dasar kemanusiaan. Pada definisi Carter (2016) memandang bahwa cinta yang dinarasikan bukan semata pada konteks dua sejoli yang sedang bermabuk kepayang. Menurut Carter; love is interesting because it is everywhere and has a significant impact on our culture, society and lives, and yet we can know relatively little about what it actually means. Jelas bahwa cinta bersifat dinamis dan mampu menyesuaikan diri, seperti cinta kepada sesama manusia, cinta kepada alam semesta, cinta kepada binatang dan tumbuhan, dan hal itu terjadi secara otomatis.

Lebih lanjut, Carter mengemukakan bahwa cinta secara sosiologis dipahami dalam beberapa pandangan yaitu: sexual love, intimate love, companionate love, romantic love, parental love, friendship love, interspecies love, love for places, belongings, views. Namun, lebih penting daripada itu cinta memainkan peran penting dalam emansipasi perempuan: bangkitnya cinta yang romantis beserta kaitannya dengan pernikahan, dalam hal ini bahwasannya perempuan semakin memiliki lebih banyak pilihan dalam menentukan pasangan masa depan mereka. Pada beberapa kultur di Indonesia masih saja terdapat 'cinta yang dipaksakan' kepada kaum perempuan. Bahwasannya budaya perjodohan yang masih terjadi ini merupakan bentuk nyata dari cinta yang maskulin; dipaksakan dan tanpa persetujuan (perempuan).

Cinta yang ada di letakkan atas dasar budaya patriarki selalu akan menjadikan pernikaha sebagai hasil akhir. Bahwasannya pernikahan merupakan pabrikasi atas cinta, yang kemudian membentuk sebuah keluarga dan melahirkan anak. Sehingga pada masyarakat yang masih kental budaya patriarki, akan sangat kaget ketika ada dua orang laki-laki saling jatuh cinta, atau dua orang perempuan saling jatuh cinta. Hal ini karena cinta selain heteroseksual (antara laki-laki dengan perempuan) dianggap tabu. Padahal semestinya cinta tidak dipandang atas dasar seksualitas dan gender seseorang, melainkan cinta membuat alam semesta menjadi sebuah tatanan yang harmonis, tempat setiap partikel tidak lagi bertengkar satu sama lain melainkan bekerja secara harmonis dengan seluruh semesta raya (Sorokin, dalam Krich, 2015). 
Niko (2016a) melihat bahwa pada cinta sejenis (cinta yang homoseksual) sejatinya adalah; bertemu, mencintai, (dan meninggalkan). Dalam hal ini terbagi ke dalam dua perspektif; pertama, bahwa pada manusia yang homoseksual, adanya cinta sangat ditentang oleh masyarakat yang utamanya mencampurkan urusan seksualitas dengan narasi agama. Sejalan dengan apa yang dikatakan Diane Richardson and Hazel May (dalam Giddens, 2006) menyebutkan: “....because homosexuals remain stigmatized and marginalized in many societies, there is a greater tendency for them to be treated as 'deserving' of crime, rather than as innocent victims." Dengan adanya stigma yang dilekatkan masyarakat kepada kelompok yang memiliki seksualitas lain di luar heteroseks, akan memperparah kuatnya narasi maskulinitas pada masyarakat. Stigmatisasi dan marginalisasi ini menurut saya adalah pembatasan cinta secara keseluruhan, yang mengarah kepada degradasi kemanusiaan.

Kedua, adanya pandangan penyimpangan dalam tujuan seksual, penyimpangan ini digambarkan sebagai perversi, kemudian adanya tujuan-tujuan seksual yang temporer. Pada dasarnya menurut Freud (2017) aktivitas-aktivitas itu sendiri berhubungan erat dengan kesenangan-kesenangan yang semestinya menuju pada pencapaian tujuan seksual akhir. Freud juga menyebutkan bahwa peran seksual dari selaput lendir anal sama sekali tidak dibatasi untuk persetubuhan di antara lelaki,dan tidak ada apapun di dalamnya mencirikan perasaan invert. Namun kemudian masyarakat melihat hal-hal tersebut sebagai sesuatu yang menjijikkan dan tidak normal. Perlu juga diketahui bahwa pada hubungan seks hetero (yang dianggap normal) pun obyek seksual normal digantikan oleh benda lain yang berhubungan dengannya, seperti yang dikatakan Freud bahwa beberapa bagian tertentu dari tubuh, seperti selaput lendir mulut dan anus, yang berulang kali muncul dalam praktikpraktik seksual telah secara efektif menyatakan hak untuk dipandang dan diperlakukan secara genital dengan caranya sendiri.

Pada orang tertentu, substitusi untuk obyek seksual untuk mengekspresikan kecintaan yaitu anggota tubuh (kaki, rambut atau obyek benda mati yang jelas berhubungan dengan organ seksual). Menurut Freud, bukan tanpa justifikasi sama sekali bahwa barang substitusi itu dapat dibandingkan dengan jimat yang dipuja manusia primitif sebagai perwujudan dewanya. Seperti narasi berikut:
Schaff' mir ein Halstuch von ibrer BrustEin Stumpfband meiner Liebeslust! -Faust- (Bawakan aku setangan dari balik dadanya, Sebelai kaos kaki kesukaan cintaku.)

Narasi Faust tersebut merupakan wujud cinta yang kemudian dikonstruksikan ke dalam bagianbagian tubuh tertentu. Hal ini turut berperan menumbuhkan cinta yang maskulin di tengah masyarakat. Akan terdapat standarisasi dalam mencintai; "aku hanya mencintai perempuan berambut lurus, berkulit putih, tinggi dan langsing". Bahwasanya cinta yang bersyarat merupakan salah satu ciri cinta yang maskulin. Sementara cinta yang selalu membuat pilihan merupakan cinta yang diskriminatif, cinta yang hanya menghendaki "perempuan ini" dan bukan yang lain (Krich, 2015).

Lalu, bagaimana dengan seni? Cinta seringkali dijadikan sebagai objek seni. Cinta yang santun ditemukan pada tiap-tiap bait puisi penyair jalanan pada abad ke-11. Seniman jalanan acapkali mengekspresikan perasaan mereka ke dalam syair puisi, mendeskripsikan perempuan sebagai makhluk berbahaya yang harus dijauhi, perempuan sebagai makhluk cantik dan mengagumkan yang perlu dihormati dan dipuja, di luar percampuran dua gagasan tentang perempuan tersebut mengalirlah erotisme munafik (Krich, 2015).

Perempuan acapkali menjadi objek dari cinta. Hal yang mengakar menjadi penyebabnya adalah budaya patriarki yang masih sangat kental dengan masyarakat kita di Indonesia. Kemudian, fakta bahwa perempuan juga acapkali mengembangkan inferior complex dan berusaha mengkompensasi dengan menjadi eksibisionis, narsistik, dan suka berdandan (Wijaya \& Ananta, 2016). Oleh karenanya, perempuan acapkali menjadi sasaran dan korban kekerasan seksual, pelecehan, perkosaan dan korban cinta.

\section{Cinta Sebagai Seni yang Erotis}

Pandangan Freud terhadap cinta bersifat sederhana dan konsisten, secara eksplisit Freud menyatakan bahwa cinta identik dengan seks (Krich, 2009). Freud lebih lanjut menjelaskan bahwa ekspresi libido merupakan perjumpaan awal antara energi cinta dan dorongan seksual. Dorongan yang dimaksud oleh Ferud yakni meliputi kasih sayang (affection) dan juga rasa ketertarikan (attraction). 
Seni yang erotis seringkali kita jumpai pada budaya seni tari yang ada di Indonesia. Biasanya menampilkan tubuh-tubuh perempuan yang melenggok indah dan cantik sehingga menarik perhatian laki-laki. Begitu pula dengan cinta yang menampilkan sisi erotis, biasanya menjadikan perempuan sebagai objek semata.

Marcuse (2004) mengungkapkan bahwa cinta akan menempuh jalur yang brutal jika di kekang, artinya bahwa penurunan kontrol sosial yang alamiah atas insting seks, bahkan dalam kondisi optimum, akan membalikkan pengorganisasian seksualitas kembali menuju tahap pra-peradaban, kemunduran ini akan menghapuskan penyaluran seks ke dalam reproduksi monogamis, dan tabutabu atas perversi. Cinta yang melahirkan kebrutalan (kekerasan) ini cenderung akan dilampiaskan kepada siapa saja, termasuk diantaranya perempuan dan anak-anak.

Tidak dibenarkan jika ada orang dewasa yang melakukan adegan seksual dengan anak-anak. Negara kita memiliki payung hukum yang kuat untuk melindungi anak-anak kita dari pelaku pedofilia. Namun, di dalam cinta sangat memungkinkan terjadi perasaan saling cinta antara anak-anak dengan orang dewasa. Adanya hubungan cinta antara orang dewasa dengan anakanak ini akan melahirkan cinta yang perlahan-lahan akan membunuh keduanya tanpa rasa sakit (euthanasia). Tidak ada satupun tempat di bumi ini yang mengizinkan adanya hubungan cinta orang dewasa dengan anak-anak tanpa ikatan keluarga. Demikianlah cinta, terkadang melampaui batas nalar yang mampu terpikirkan oleh akal sehat.

Berdasarkan pendapat Marcuse yang menyebutkan bahwa cinta semestinya memiliki keluwesan, kebebasan dan dinamis. Dalam arti lain bahwa cinta tidak memiliki batasan ruang dan waktu. Hal ini masih relevan dengan fenomena di era digital masa kini, dimana banyak orang menjalani hubungan melalui dunia maya (media sosial), mereka memiliki ikatan yang kuat dan bahkan saling jatuh cinta tanpa adanya pertemuan. Cinta dialami sebagai kesenangan yang sedemikian dekat, harapan pada pengetahuan yang penuh terhadap satu sama lain, kerinduan untuk saling mengidentifikasikan dan menyatukan kepribadian.

Cinta itu seni, yang dapat membawa kita kepada keindahan. Seperti yang dikatakan Sorokin (dalam Krich, 2015) bahwa cinta itu etis yang identik dengan esensi kebaikan, tidak terpisahkan dari kebernaran dan keindahan. "Penderitaan cinta sedemikian panjang, dan selalu penuh kasih. Cinta tak pernah merasa iri. Cinta tidak pernah menyakiti dirinya, tak pula menguap, tak pernah berbuat yang tak pantas, berbuat tak hanya untuk dirinya," Sorokin (dalam Krich, 2015).

Hasil penelitian Helen Fischer dari University New Jersey yang kemudian diulas oleh Fromm dalam pengantar untuk buku Freud (2009), menyebutkan bahwa seks sebagai naluri dasar manusia memiliki keterkaitan erat dengan cinta, yang mana proses jatuh cinta ini melalui 3 (tiga) tahap, yaitu: a) nafsu, hal ini didorong oleh hormon seks testosteron dan estrogen. Hormon inilah yang menurut Helen Fischer sebagai faktor yang "membuat anda keluar mencari sesuatu", maksudnya adalah laki-laki mencari pasangan perempuan, dan sebaliknya; b) daya tarik, yang merupakan tahap dimana cinta beritu mengena.

Orang-orang yang sedang jatuh cinta tidak bisa memikirkan hal-hal lain daripada cinta itu sendiri. Mereka bisa kehilangan nafsu makan, tidur lebih sedikit, serta lebih suka menghabiskan waktu berjam-jam untuk melamun kekasih baru mereka. Pada tahap ini, seperangkat neurotronsmiter dalam tubuh kita mulai bekerja, seperti Domapin (yang juga bisa diaktifkan dengan kokain dan nikotin), Norepinefrin atau dikenal dengan adrenalin (yang membuat kita mulai berkeringat atau berpacu jantung ketika jatuh cinta) dan Serotonin (yang membuat kita menjadi seperti orang gila); c) kasih sayang, tahap ini yang menggantikan tahap daya tarik, ketika dua insan menginginkan hubungan mereka bertahan.

Beauvoir (dalam Krich, 2015) berpendapat bahwa laki-laki dan perempuan memiliki pemaknaan yang berbeda tentang cinta. Kata cinta senduru menandakan dua hal yang berbeda diantara laki-laki dan perempuan. Pemahaman perempuan tentang cinta, cukup jelas: cinta tidak hanya pengabdian tetapi juga menyerahkan seluruh jiwa raga tanpa syarat, tanpa mengharapkan penghargaan dalam bentuk apapun (Nietzsche, dalam Krich, 2015). Makna cinta bagi perempuan ini yang saya sebut sebagai cinta yang feminin, mengandung kelemahlembutan, pengabdian dan agung. Sementara cinta yang maskulin menempatkan cinta sama dengan seks, atau setidaknya cinta selalu disimbolkan dengan adanya hubungan seks (erotis). 
Konsep Freud (2009) yang menyebutkan bahwa cinta sebagai seks yang telah ditangkap atau dijauhkan dari tujuannya-tetapi secara esensial sama dengan gairah seksual yang mentahmemberikan kesan bahwa keduanya merupakan materi yang homogen, dengan kata lain bahwa cinta dan seks sama jenisnya. Berbeda dengan Stendhal (dalam Krich, 2015) menyebutkan bahwa variasivariasi secara seksual itu sebagai suatu gairah, cinta atas dasar simpati, cinta sensual dan cinta yang siasia. Niko (2016c) menyebutkan bahwa di dalam praktik-praktik prostitusi bahkan terjadi atas dasar cinta yang menggebu. Tetapi dalam hal ini tidak ada cinta yang tidak manusiawi, orang yang dikehendaki sebagai objek seks dan objek cinta bisa saja dua orang yang berbeda, atau bisa saja satu orang yang sama (Krich, 2015).

\section{Paradoksal Maskulinitas Cinta}

Cinta yang maskulin tidak akan dapat terlihat secara langsung, melainkan ditelaah melalui emosional yang kemudian mampu menafsirkan bahwa terdapat cinta yang maskulin dalam masyarakat kita. Cinta yang maskulin merupakan bagian daripada kehidupan setiap manusia, dalam arti lain bahwa manusia tidak dapat terpisah dari emosional cinta yang maskulin. Baik laki-laki maupun perempuan bisa saja menjadi aktor cinta maskulin. Pada pembahasan di awal disebutkan bahwa budaya perjodohan yang masih terjadi di tengah-tengah masyarakat di Indonesia merupakan bentuk nyata dari cinta yang maskulin. Adanya internalisasi ideologi gender yang maskulin masih terjadi pada masyarakat kita di Indonesia hingga hari ini, sehingga tidak dapat dipungkiri kultur masyarakat kita sarat dengan budaya yang patriarkis.

Menikah bukan sesuatu hal yang harus dipaksakan, bukan? Jika terdapat salah satu pihak yang terpaksa (secara emosional), maka dapat dikatakan bahwa terjadi dominasi cinta yang maskulin terhadapnya. Seperti yang diungkapkan oleh Fowler (2007) bahwasannya menikah adalah jalan bagi dua insan dewasa untuk saling mengerti cinta mereka satu sama lain. Insan disini tidak hanya bermakna laki-laki dengan perempuan saja, melainkan juga dalam konteks pernikahan laki-laki dengan laki-laki, maupun perempuan dengan perempuan, pada cinta yang maskulin hal ini tidak berlaku sama sekali.
Cinta yang maskulin penuh dengan persyaratanpersyaratan, "aku mencintaimu karena kamu cantik", "aku mencintaimu karena kulitmu putih", dan lain sebagainya. Narasi-narasi tersebut merupakan maskulinitas cinta yang seringkali tidak kita sadari, kita berpikir bahwa lumrah saja jika cinta selalu bersyarat. Pada sosiologi cinta yang dikemukan Charter (2015) bahwa cinta itu nonaggression, artinya bahwa cinta tidak melakukan penilaian-penilaian atau pun penyerangan fisik secara lisan. Dengan kata lain bahwa pandangan sosiologi cinta tidak memandang cinta penuh syarat, justru sebaliknya cinta yang tanpa syarat.

Amstrong (2014) menyebutkan: "Love is not inherently sacrificial, even if - for reasons of love-one gives up some freedoms that might have been retained under other circumstances". Dari pernyataan tersebut dapat disimpulkan bahwa cinta sama sekali tidak mengungkung seseorang untuk tunduk kepada seorang lainnya. Cinta sangat menghargai kesetaraan, dan tidak mendominasi. Berbanding terbalik dengan cinta maskulin yang menghamba pada narasi seksual. Seorang perempuan dituntut menjaga keperawanan sampai pada saat mereka dinikahkan dengan seorang laki-laki. Penghambaan seksual ini menurut Kraff-Ebing (1892, dalam Freud, 2017) merupakan tingkat yang tidak umum dari cinta yang bergairah dan lemahnya karakter, dalam hal ini saya sependapat dengan Reik (dalam Krich, 2015) bahwa cinta dan seks itu tidak sama.

Terdapat penyimpulan orang-orang lain terhadap seks dan cinta, bahwasannya kedua hal ini saling tak terpisahkan. Bagi saya peletakan dasar cinta pada seks semata adalah cinta yang egois. Cinta yang egois adalah cinta yang meletakkan label jenis kelamin, agama, suku, ras, atau berbagai macam lainnya. Sama halnya dengan cinta yang bersifat diskriminatif, hanya mencintai manusia pada kriteria tertentu saja, bukan atas dasar cinta terhadap kemanusiaan yang ada di dalam diri manusianya.

Fenomena menarik yang saya temukan ketika saya berada di tengah-tengah masyarakat suku Dayak Benawan dan Dayak Mali di daerah pedalaman Kalimantan Barat, terdapat satu kebiasaan tidak ingin menikah yang mereka sebut Pogo'k. Pada orang tertentu di dalam masyarakat tersebut yang memilih hidup Pogo'k, lebih karena mereka mencintai keluarga, dan mereka mencintai kesepian dalam hidup mereka. Saya tidak menyetujui pendapat Sorokin (dalam Krich, 2015) 
yang menyebutkan bahwa cinta akan menyingkirkan kesepian dan mengikat kita dengan ikatan paling mulia dengan orang lain. Bahwasannya, terdapat kelompok masyarakat yang meyakini bahwa mencintai kesepian itu sendiri adalah hal yang wajar.

Kebiasaan hidup Pogo'k ini sendiri bukan tanpa alasan, bagi masyarakat di dua kelompok suku itu (Dayak Benawan dan Dayak Mali) meyakini bahwa seseorang yang memilih untuk hidup Pogo'k penuh dengan tanda-tanda misktik. Asumsi-asumsi masyarakat mengenai Pogo'k, yaitu: Pertama, orang yang hidup Pogo'k diikuti oleh roh halus sehingga siapapun yang ingin menikah dengannya maka akan meninggal dunia. Kedua, orang yang memilih hidup Pogo'k diyakini akan berumur panjang. Ketiga, orang yang hidup Pogo'k memiliki peliharaan rohroh halus.

Menurut saya, orang yang memilih hidup Pogo'k bisa jadi karena selama masa mudanya belum menemukan tambatan hati (cinta sejatinya). Atau bisa jadi karena mahalnya biaya perkawinan di dalam budaya setempat. Cinta itu unik, cinta itu sesuatu yang tidak pernah kita bayangkan sebelumnya (Freud, 2017). Bisa saja Pogo'k terjadi karena kecintaan seseorang terhadap dirinya sendiri. Atau melebihi itu, Pogo'k terjadi karena adanya stimulus cinta kepada sesuatu hal yang tidak tampak, kemanusiaan. Seperti halnya banyak orang yang kemudian memilih untuk tidak menikah karena panggilan kemanusiaan, melayani orang banyak dan meninggalkan kehidupan duniawi.

Fenomena Pogo'k di dalam kelompok masyarakat Dayak Benawan dan Dayak Mali ini lebih banyak terjadi pada laki-laki. Sejauh penelusuran saya, belum menemukan Pogo'k yang terdai pada perempuan. Alasan mengapa tidak ada perempuan yang hidup Pogo'k adalah karena perempuan merupakan pnerus generasi dengan melahirkan. Oleh karena itu jika ada perempuan yang belum menikah di usia yang sudah tua akan di stigma oleh masyarakat. Sedangkan bagi laki-laki, Pogo'k adalah pilihan.

Cinta yang maskulin kerapkali berupa deklarasi yang bersifat permintaan dan pemaksaan. Dengan adanya pemaksaan bagi perempuan untuk menikah, dan tidak adanya pilihan bagi perempuan untuk hidup Pogo'k merupakan narasi maskulinitas cinta yang hidup di tengah-tengah kelompok masyarakat. Jika Pogo'k merupakan pilihan hidup bagi laki-laki, semestinya Pogo'k juga merupakan pilihan hidup bagi perempuan. Dengan adanya keterpaksaan bagi perempuan untuk menikah, akan melahirkan berbagai ketidakadilan seperti kekerasan dalam rumah tangga, pelecehan seksual, dan kekerasan seksual. Semua ketidakadilan itu diletakkan atas nama cinta. Padahal cinta yang afektif adalah cinta yang melindungi, tidak egois dan kebaikan (Sorokin, dalam Krich, 2015).

Sebenarnya narasi cinta yang terbangun, pada deklarasi tersebut sarat dengan syarat, maksud saya cinta simbolik yang harus dimaknai dengan emosi jiwa atau perasaan. Semisal: "aku ingin kau memuaskan diriku" atau "aku ingin mengeksploitasi kecantikanmu", deklarasi ini tidak berbeda artinya dengan "kuharap kau berikan cintamu seutuhnya kepadaku". Krich (2015) menyebutkan bahwa cinta itu tidak kaku dan egois, cinta selalu memikirkan kesejahteraan atau kesenangan orang lain, menyesali ketidakhadirannya, ingin bersama dengan objeknya, merasa kesepian tanpanya, takut atas malapetaka atau bahaya yang menimpa objeknya.

\section{Ucapan Terima Kasih}

Artikel ini merupakan perluasan atas kajian Sosiologi Cinta yang pernah saya tulis sebelumnya. Artikel ini dapat terselesaikan karena semangat dan masukan dari beberapa temanku; Rahman Latif Alfian, Atem, Faraz, dan Anisa Shinta. Terima kasih pula kepada Ibu Rupita yang memberi masukan tentang budaya cinta pada masyarakat di daerah. Kemudian terima kasih kepada LPDP (Lembaga Pengelola Dana Pendidikan) Kemenkeu RI, yang pernah memberikan kesempatan kepada saya untuk meneliti masyarakat Dayak di Kalimantan Barat, sehingga fenomena yang saya jumpai disana dapat memperkaya tulisan ini.

\section{PENUTUP}

\section{Simpulan}

Cinta sudah idealnya bermakna tidak mendominasi, cinta tidak saling menyakiti, dan cinta membawa terang damai bagi kehidupan manusia. Seperti yang diungkapkan Sorokin (1950) mengenai makna cinta sebagai kekuatan dinamis yang mengubah wujud manusia secara efektif, memuliakan institusi sosial, menginspirasi kebudayaan dan membuat dunia menjadi kosmos yang hangat, bersahabat dan indah. Demikian dengan seks, cinta sama sekali tidak sama dengan 
gairah seksual. Seks adalah kebutuhan biologis, bermula di dalam organisme dan terikat pada tubuh. Seks muncul sebagai fenomena alam yang umum terjadi pada manusia dan hewan. Sementara cinta adalah hasil dari perkembangan kebudayaan dan tidak bisa ditemukan pada semua manusia.

Penciptaan narasi cinta semestinya meliputi konsep penghargaan, keberanian, kesetiaan dan nilai-nilai estetis maupun etis yang adalah bagian dari lingkungan simbolik kehidupan manusia. Disadari maupun tidak, cinta yang tergambar pada lingkungan kita selalu bersifat individualistik dan terlalu substantif (kaku), sehingga cinta yang seperti ini cenderung mengarah kepada cinta yang maskulin. Ketundukan kita pada kultur misalnya, kemudian menciptakan simptomatologi cinta pada diri kita sendiri.

Bentuk lain dari ketidakadilan terhadap perempuan seperti pelecehan seksual, pemerkosaan dalam kencan (pacaran) dan pemerkosaan marital, kekerasan dalam rumah tangga, semuanya dijelaskan melalui dominasi patriarkis (Wijaya dan Ananta, 2016). Kejahatan oleh laki-laki ini merefleksikan kemampuan lakilaki untuk menggunakan kekuasaan atas perempuan. Dalam urusan percintaan pun, bahkan perempuan acapkali menjadi korban cinta. Korban PHP (pemberi harapan palsu), korban perasaan/psikis (diselingkuhi), bahkan korban fisik (kekerasan seksual). Cinta tidak menempatkan siapapun sebagai korban.

Cinta sejatinya adalah tanpa syarat apapun. Kita dengan senang hati dan penuh bahagia mencintai manusia lainnya, hewan, tumbuhan, mencintai alam sekitar, negara dan bangsa, serta mencintai bumi ini. Tidak ada persyaratan apapun dalam mencintai, yang ada adalah menebar kasih dan damai dimana kehidupan. Saya mengingat Bunda Teresa yang mengatakan "apa yang dapat anda lakukan untuk mempromosikan perdamaian dunia? Pulanglah dan cintailah keluargamu", bahwasannya keutamaan dari cinta adalah perdamaian.

\section{DAFTAR PUSTAKA}

Amstrong, K. (2014). Love: Perspective from Sociology, Philosophy and Religious Studies. http://whatwhen-how.com/love-in-worldreligions/love-perspectives-from-sociologyphilosophy-and-peligious-studies/ Diunduh tanggal 6 Februari 2018, pukul 16.12 WIB.
Charter, J. (2015). The Sociology of Love. https://www.thesociologicalreview.com/bl og/the-sociology-of-love.html Diakses tanggal 8 Februari 2018, pukul 9.25 WIB.

Fowler, A., C. Love and Marriage: Through the Lens of Sociological Theories. Human Architecture: Journal of the Sociology of SelfKnowledge. Vol. 5, Issue 2, (2007), P. 61-72.

Freud, S. (2009). Pengantar Umum Psikoanalisis. Yogyakarta: Pustaka Pelajar.

Freud, S. (2017). Cinta yang Tak Semestinya: Deviant Love. Surabaya: Ecosystem Publishing.

Giddens, A. (2006). Sociology (Fifth Edition). Cambridge: Polity Publishing.

Krich, A., M., (Ed). (2009). Anatomi Cinta: Risalah Jalan Cinta, Arti Cinta \& Kekuatan Cinta. Jakarta: Komunitas Bambu.

Marcuse, H. (2004). Cinta dan Peradaban. Yogyakarta: Pustaka Pelajar.

Niko, N. (2016a). Cinta Tak Seharusnya Pergi. https://www.qureta.com/post/cinta-takseharusnya-pergi Diunduh tanggal 12 Februari 2018, pukul 23.11 WIB.

Niko, N. (2016b). Realitas Cinta Sejenis: Perspektif Sociology of Love. www.suarakita.org/2016/03/opini-realitascinta-sejenis-perspektif-sociology-of-love/ Diunduh pada tanggal 8 Maret 2018, pukul 21.20 WIB.

Niko, N. (2016c). Boy Prostitute: Kemiskinan dan Life Style. Yogyakarta: Deepublish.

Popova, M. (2016). Why Love Hurts: The Sociology of How Our Institutions Rather Than Our Personal Psychological Failings Shape the Romantic Agony of Modern Life. https://www.brainpickings.org/2016/03/2 2/why-love-hurts-eva-illouz/ Diunduh tanggal 6 Maret 2018, pukul 10.11 WIB.

Shiva, V. (1997). Bebas Dari Pembangunan: Perempuan, Ekologi dan Perjuangan Hidup di India. Jakarta: Yayasan Obor Indonesia.

Sorokin, P. (1950). Altruistic Love. Boston: Beacon Press.

Wijaya, A., \& Ananta, W. P. (2016). Darurat Kejahatan Seksual. Jakarta: Sinar Grafika. 